\title{
Editorial: Messages, metaphors and looking for love: The Internet, Year 2000
}

The Internet changes everything. And everything changes the Internet. How fluid it is, how quick and how intertwined with the physical world, which it mirrors, and which, increasingly, mirrors it. Perhaps reality and virtual reality are not opposites but complements, wrapped around each other like strands of DNA.

Look at the metaphors we use. The Love Bug virus crisis highlights the biological cast of the Internet imagery - worm, bug, virus. Rich and rapid caches of information are described as 'robust', a word the Oxford English Dictionary grounds firmly in the world of living organisms. And how technological our images have become in speaking about ourselves: 'She's programmed to embellish the truth', someone said to me yesterday. 'It's a web', remarked a psychologist, talking about depression.

The metaphors wrap around each other like strands of DNA also, perhaps bringing us a message from the distant or (according to people like Ray Kurzweil, author of 'The Age of Spiritual Machines') not so distant future, when humans and machines interpenetrate each other.

Major Internet events whirl around at warp speed, tectonic plates on amphetamines. My own sense of recent periodicity goes back to 1998 , visits 1999, and tries to keep up with things now that we are in the 21 st century. They talk about Internet time, the lightning rhythm that is fast becoming the pace of our lives. I think they are right.

\section{FIVE WATERSHED EVENTS}

FROM ANCIENT HISTORY (1998)

\section{The Starr report}

The Starr report on Bill Clinton was disseminated via the Internet. This was the first time that a major public/government event appeared on the Internet prior to other media. The news was out on the Internet first, and millions of people accessed it. When future histories are written, the Starr report may bear the same relationship to Internet development as the Army/McCarthy hearings did to television.

\section{The Procter \& Gamble conference in 1998}

Procter \& Gamble invited competitors, consultants and Internet agencies to discuss the failure of Internet advertising. Experts pointed out that no one had coined a memorable slogan on the Internet. Even worse news: as people 
get more Internet-literate, they begin ignoring banner advertisements. The conclusion (which is pretty obvious if you understand media) was reported in multi-page stories in both The New York Times and The Wall Street Journal: the Internet is a direct marketing medium, not an advertising medium.

Advertising is a right brain communications discipline. It works best on television (a right brain medium), ideally by inculcating shards of impressions into the passive brains of half-alert couch potatoes. As soon as you call for behaviour, the spell is broken.

The Internet, like direct mail, is an interactive medium, by definition left hemisphere. The advertising industry wants the Internet to be like television, but it cannot be, as the wrong part of the brain is involved. It takes time to sort all of this out. Marshall McLuhan said 'Media are put out before they are thought out'. But the sorting has begun.

\section{Amazon.com's book 'recommendations'}

Amazon.com customers had been happily allowing the company to guide their book choices via customerwritten reviews. The New York Times revealed, though, that Amazon was quietly selling these reviews to publishers. Amazon at first defended the practice as analogous to the publisherfunded displays seen in bookstores, but it quickly backed down.

What this showed was how the Internet is changing commerce. The personalised, interactive, somewhat tribal relation customers have with Amazon.com made the promotions seem like betrayals. It is due to what Dave Pottruck, CEO of Charles Schwab, calls the 'social fabric' of Internet commerce. Interactivity creates involvement, which can easily become emotional involvement. The passive experience of browsing through a large bookstore lacks the interactivity, and therefore the emotional charge that made Amazon customers think they had been suckered. Also adding to the emotional charge: a compensation reaction to the disembodiment and abstraction of the Internet.

Amazon.com may be a business, but it acts like a club. Internet commerce, at least in its early stages, seems to want to be club-like. Apropos which, Amazon's Jeff Bezos reminds us in an advertisement that word-of-mouth on the Internet becomes a mass medium. Companies now stinting on service, and there are many, should pay attention.

\section{The explosion of e-commerce in the USA}

Everyone, most notably the merchants themselves, was taken aback at the unexpected growth of Internet buying during the 1998 holiday season. It was not precisely a success. Inventory and shipping problems created massive consumer disappointment, a reminder of the rude way physical reality intrudes into cyberspace. But it is par for the course for new media and new 
channels to suffer logistical growing pains.

E-commerce is exploding because of a classic intersection between technological adaptation and consumer needs. Catalogues in the USA exploded for the same reasons: technological adaptation to 800-numbers and credit cards, and impatience with the time-consuming, service-deficient nature of conventional retail buying.

\section{Priceline.com}

Early stage technologies invariably pour old content into new forms. In the beginning, television consisted of live drama and vaudeville acts. The new medium only knew the messages of theatre and radio. Film in those early days seemed like the wrong message - why do movies when you can broadcast live? (In retrospect, the live dramas of the 1950 s seem like bad cinema, rather than good television.) Advertising was off base also, with most commercials at first being direct response, the wrong mode for such an essentially passive, right-hemisphere medium. It took a few years before messages grew into the medium, and video, the most powerful media form of the last half of the 20th century emerged, as did image advertising, the most powerful commercial communications form.

What we now call e-commerce (which, for sure, is a transitional term) is mostly old content. For all the technical legerdemain of Amazon.com, you can duplicate the experience in the physical world.
Priceline.com is different, though. A new kind of message for a new kind of medium. Listen to what Priceline impresario Jay Walker says in an interview: ${ }^{1}$

'In the traditional model of commerce, a seller advertises a unit of supply in the marketplace at a specified price, and a buyer takes it or leaves it. Priceline turns that model around. We allow a buyer to advertise a unit of demand to a group of sellers.'

Wow! But what is in it for the seller? Can this be (I hate the expression) the classic Win-Win? Maybe.

'The Priceline system... enables sellers to see, for the first time really, the latent demand in the marketplace - the demand that exists beneath the established price of the product or service. And because the customer's offer is irrevocable, guaranteed with a credit card, it's real demand - the seller can count on it...

Because the seller is anonymous through the buying process, it gets two clear benefits in addition to the incremental sales.

First, it gets a brand shield. If it had publicly advertised a lower price for its product or service, it would have eroded its brand. But since it can accept the unit of demand without letting the buyer know the brand in advance, it suffers no such erosion. 
Second, the seller gets a price shield. It can maintain the integrity of its established prices because it never advertises that a lower price is being billed. The seller avoids the problem of free riders - people who take a discounted price even though they would have been willing to pay the full price.'

Wow, again!

\section{THREE KEY PHENOMENA OF RECENT HISTORY (1999)}

\section{9: The year of the bubble (postmodern tulip mania)}

Dotcom fever swept the markets away, ignoring both the laws of economic gravity and the marketplace. The Second Law of Thermodynamics always kicks in, as it has now done. Plus, sooner or later you need customers. You will not get any, though, if you are offering solutions for which there are no problems, the case in so many of the pure-play dotcoms.

Bubbles always burst, and new technologies always proliferate into multiple organisms, few of which survive. There were something like 170 US car manufacturers in the early years of the last century. It did not take long for most of them to fail, but the car became (along with radio and the telephone) the most important technology of the first half of the 20th century. Similarly, Peapod might fail, the NASDAQ might crash and Amazon might go under, but all of these events would be typical of early stage technologies, and would have no relevance to the Internet's impact on 21 st-century economy, culture and society.

\section{From surfing to searching}

Surfing has always been a bad metaphor, as Steven Johnson points out in his brilliant book, 'Interface Culture'. It is borrowed from television channel surfing, and the Internet is emphatically not like television. Advertising agencies will remain confused about this for some time, they are hung up on the screen, panicked about the Internet bleeding budgets from television, and ignorant about the nature of media and human cognition. Television is right hemisphere, the Internet is left hemisphere, and the twain do not meet.

The Internet is about searching, not surfing. It is about links and connectivity, not about the mindless discontinuity of television channel surfing. In 1999, we started to hear the expression 'surfing the net' less and less, and more and more, 'I got a good deal on eBay'. When technologies begin to mature, the machine drops out of the language. In the early days of television, neighbours used to come over to my parents' house to watch television. When television became a mass medium, people began to look at shows, rather than 'watch TV'. Our metaphors are more important than our statements.

\section{US banner adverts}

The click rate on banner adverts almost zeroed out in the USA. Banner adverts, 
at least in their customer acquisition incarnation, work only when people are surfing. As mentioned above, searching is the real Internet mode, and when you are searching, you do not have time or attention for extraneous matter. Hence, the almost disappearing click rate on banner adverts.

Most banner adverts are old content poured into new forms. If you use banner adverts to cross-sell to existing customers, and build them according to direct marketing principles, with an offer and a reason for clicking, you can be successful. But you can also do the same thing with a link, at less cost, and get prospective customers to your form sooner.

\section{ELEVEN WATERSHED EVENTS OF YEAR 2000}

\section{Shards of bubble descend as laws of economic gravity assert themselves}

Maybe by the time this editorial appears, the NASDAQ and tech stocks will have bounced back. But, at the time of writing, the pure-play dotcom game seems to be over, with 'bricks and clicks' now the flavour of the month - or maybe year.

Far be it from me to give investment advice, but the e-commerce outfits most likely to survive are the big brands who are willing to embrace the new technologies, and the new companies, Priceline might be an example, who do something that cannot be duplicated in the physical world.

\section{Bricks and clicks: Interpenetration}

Marshall McLuhan points out that media go through a growth spurt when a new medium and an old medium combine. He calls this interpenetration. For example, 72 per cent of US radio commercials are now direct response, a result of a new medium (cell phones) interpenetrating the old medium (or space) of radio drive time. The old medium of movies interpenetrated the new medium of television, which became the major distribution channel for movies, able to accommodate both conventional films and those made expressly for broadcast.

The Internet does not replace physical reality, it complements it. Big brands and big stores are now getting smart about the Internet, recognising that a new medium does not render old media obsolete - it changes the role of the old media. So the grocery store is now the place to go to buy meats and produce, but the Internet is for staples and packaged goods. You bank on-line until you need to talk to someone about your pension plan, and then you go into a branch, which is now located in a supermarket, rather than a free-standing brick and mortar edifice.

\section{AOL/Time Warner merger: Interpenetration, again}

Another example of interpenetration, this time old media and new media, in the largest sense of the word, including content. McLuhan said that the 
message of every medium is another medium. If so, the message of Time Warner content could well end up being the continued conventionalisation of AOL, already the Internet's equivalent of apple pie and motherhood. This is the economic version of Herbert Marcuse's concept of 'repressive tolerance', AOL effectively colonising the wild and threatening terra incognita of the Internet.

The implications of this merger are disturbing. There is too much message/media mass here to be healthy, and one of the dramas of the next few years will be the concentration, and therefore control, of so much 'information' on the part of multinational behemoths, beholden to no one but their shareholders. 'News' is already managed, controlled, and distorted to a state of perfection

What a pity if the anarchic, anything goes ethos of the Internet rumbles down the road of pure post-industrial capitalism, never to return. (In 1993, Bob Dylan said 'Technology to erase the truth now exists. Wait until the cost comes down!')

\section{DoubleClick: Privacy (echoing into census reaction)}

This was a big one. The first time Americans really got upset en masse about privacy. DoubleClick wanted to crossmatch e-mail addresses against physical addresses, building a dynamite (in both senses of the word) database. A more or less spontaneous consumer rebellion occurred, and DoubleClick backed off.
An echo of this event took place soon afterwards, when Americans became shy about filling in their census forms, particularly the long form with its intrusive questions.

This is taking place in a world where the US Direct Marketing Association is still trying to persuade its members to offer opt out. Beware: the privacy apocalypse in the USA is only a matter of time, unless the Federal Government saves us from ourselves. And we are in pretty bad shape if we need the Feds for salvation.

\section{Big three car makers: Disintermediation, transparency}

Daimler-Chrysler, General Motors and Ford, the three Horsemen of the Industrial Age, got together and decided to do all of their parts purchasing on the Internet. This represents about US\$350bn a year, according to the press. It also represents the ascendancy of the Internet in the business-to-business sphere, which is where e-commerce action is likely to be over the next few years.

This is also an example of both disintermediation and pricing transparency. Inventories and delivery times are all on-line, there are no salespeople and (theoretically) everyone can price dynamically, based on fundamental principles such as supply and demand, and just-in-time delivery. Out go the schmoozing, the boozing and the old boy network. Other industries, including packaged goods firms, are following suit. 


\section{Supreme Court's ruling on Microsoft}

Early-stage technologies have brittle interfaces, and a specific vocabulary (this was touched on above). The first cars had to be cranked to start, and people said, 'Let's drive in the motorcar and visit grandmother'. When key ignition eliminated the brittle interface, people said, 'Let's visit grandma'. When the interface becomes simplified, the technology drops out of the language. 'Let's drive in the motorcar and visit grandmother' is structurally the same formulation as 'Let's boot up the PC and surf the Internet'.

The personal computer, with its keyboard, mouse and Windows software, is a classic example of a brittle interface. The secret to interface simplicity, to paraphrase MIT's Nicholas Negroponte, is to make the interface disappear. Microsoft has been a force of resistance. Microsoft does not like the Internet, and in fact was dragged into the Internet world kicking and screaming. On the Internet, software can be downloaded for free. This is somewhat threatening to Microsoft's core business.

We now have non-PC Internet access devices on the market, but they are essentially stripped down PCs. Next, there will be a button to be pushed, and after that voice recognition (the technology is there, but the price has to come down a long way). After that, the Internet will be distributed through screens plural (rather than a screen) and through non-screens, eg the silicon- chipped doorknob that will open and close the door on voice commands, just in time for arthritic old baby boomers to benefit.

\section{Cisco market cap exceeds Microsoft}

When the Cisco market cap exceeded Microsoft it demonstrated that the Internet is more important than software. An important enough difference for Wall Street to notice. Software itself (at least as we now know it) is an earlystage manifestation, having to be written, downloaded, rewritten, debugged and coped with. You do not need to download software when you drive a car.

\section{Stephen King's novel}

Stephen King's Internet-published bestseller was not Saul Bellow, or even top drawer Stephen King for that matter, but it did get lots of readers. It will be part of the future history of the Internet.

Reading extensive text on the screen gives one a headache. Nicholas Negroponte has a vision of downloading texts into a book or newspaper-like device, which would give the fluidity of the Internet along with the tactile comfort of the printed form.

\section{AT\&T}

CEO Michael Armstrong is betting the company on a transformation from a tired old long distance telephone carrier to the main source of broadband transmissions in the USA. This is urgently important, to say the least, 
both for AT\&T and the Internet. The faster new technologies like T1 (and Digital Subscriber Lines, for that matter) can penetrate US households, the faster the brittle interface will disappear. When the Internet is on, as opposed to being dialled up, the effect of the technology changes dramatically.

\section{Ford employees}

Ford motor company has given all its employees free home PCs. We are such business boosters in the USA. It is one of our strengths (nothing wrong with being rich and powerful) and one of our weaknesses (there is a lot wrong with buying into business hype and propaganda).

The mainstream press has greeted Ford's generosity with hosannas, and fails to see the other side of the equation. Yes, Ford is being generous, but there are strings attached. What looks like empowerment can also be seen as a mode of social control. With home PCs, Ford may be able to grind extra work out of its knowledge workers, and also keep tabs on people. Remember, the Internet monitors users even more than they monitor it.

\section{The love bug}

What a mess, and what a metaphor. At the beginning of the editorial, I talked about biological metaphors (like bug) being used for the Internet, and technological metaphors ('he's hard-wired for success') being used for human beings. The love bug, clumsy though it was, is a message from the future, both that far distant (or maybe not) future when biology and technology intertwine, but also that nearer future, when we learn for the thousandth time that our creations soon slip out of our control. That is the bad stuff. The good stuff (in a way) is that thousands of people who should have known better opened the virus-infected document, because they were looking even in the brave new high-tech world of the 21st century - for love.

JIM ROSENFIELD

Editorial Board

September, 2000

\section{REFERENCE}

1 Harvard Business Review, NovemberDecember 1999. 
